\title{
Quem tem mais interesse pelo uso da informática na educação? Os professores mais jovens ou os mais velhos? - Um estudo correlacional
}

\section{Who has more interest in the use of computers in education? Teachers younger or older? - A study of correlation}

\author{
André Cruz Mendes \\ Faculdade Ingá. \\ CEP: 87035-510. Maringá, PR. \\ andrecruzmendes@gmail.com
}

\author{
Dante Alves Medeiros Filho \\ Universidade Estadual de Maringá. \\ CEP: 87020-900. Maringá, PR. \\ dante@din.uem.br
}

\author{
Itana Maria de Souza Gimenes \\ Universidade Estadual de Maringá. \\ CEP: 87020-900. Maringá, PR. \\ itana@ din.uem.br
}

\begin{abstract}
Resumo Atualmente convivem na sociedade gerações de pessoas que diferem entre si no trato com a tecnologia. Com base na desenvoltura com que dominam as mídias, uma primeira observação sobre essas gerações pode sugerir uma ruptura radical entre os mais novos e os mais velhos, mas essa perspectiva é falha. Estudos mostram que não existe uma classe de pessoas de mais idade resistentes à informática e que a geração dos mais jovens não deve ser vista como homogênea $[3,5,16]$. Isto vale para o contexto educacional, que conta com professores de diferentes gerações. Então, dado o interesse que os docentes têm pelo uso da informática na educação, estaria o nivel de tal interesse correlacionado à idade do professor? Caso sim, seriam os jovens os mais interessados ou seriam os mais velhos? Este é um importante aspecto a ser considerado na caracterização do perfil do usuário no desenvolvimento de software educacional, bem como na identificação do público-alvo de cursos de formação docente que abordam assuntos relacionados à tecnologia. Assim, o presente trabalho realiza um estudo de correlação entre as idades de vários professores e diversos indicadores de seus respectivos níveis de interesse com o objetivo de responder esses questionamentos. O presente estudo se apoia no contexto de um curso de extensão a distância de formação docente para a produção de objetos de aprendizagem e discute as possibilidades de generalização de seus resultados.
\end{abstract}

Palavras-Chave: tecnologia na educação, formação de professores, interesse por tecnologia

\begin{abstract}
Currently, generations of people who differ due to the use of technology are living in the society. Based on the ease with which dominate the media, a first observation about these generations may suggest a radical break between the younger and the older, but this perspective is flawed. Studies show that does not exist a class of older people resistant to computers and that the younger generation should not be seen as homogeneous $[3,5,16]$. This applies to the educational context, that includes teachers from different generations. Thus, given the interest that teachers have on the use of computers in education, would be the level of this interest related to the age of the teacher? If yes, who has more interest? The younger or older teachers? This is an important aspect to be considered in the characterization of the user profile in the development of educational software, as well as in the identification of the target audience for teacher training courses that approach issues related to technology. So, based on a study of correlation between the ages and indicators of teachers' interest that participated of an extension course at distance for the production of learning objects, this paper aims to answer these questions and discusses ways of generalization of its results.
\end{abstract}

Keywords: technology in education, teacher training, interest in technology 



\section{Professores jovens e velhos}

As tecnologias de informação e comunicação têm evoluído rapidamente, sobremaneira nas últimas duas décadas. Contudo, em âmbito nacional, embora a maioria dos domicílios tenham acesso à Internet [1], ainda existem pessoas que não se habituaram com os preceitos da vida baseada na informática. Atualmente, diferentes gerações convivem na sociedade. Essas gerações não são distantes em idade uma da outra, mas podem diferir entre si no trato com a tecnologia.

Para [2], os jovens da atualidade, nascidos entre 1982 e 2002, constituem a geração Net, que é filha da geração $X$ e neta dos Baby Boomers. A época em que esses jovens nasceram é muito diferente da época de seus avós. Essa diferença pode acarretar divergência de opinião, valores e hábitos. Segundo [3], as pessoas de mais idade geralmente se interessam por aquilo que pode lhes ser útil, atendendo suas necessidades cotidianas ou reforçando o vínculo social e familiar. Assim, o interesse dos mais velhos pela tecnologia está relacionado à integração com o mundo contemporâneo e à proximidade com as gerações dos filhos e netos. Mas, de acordo com [2], os jovens da geração Net são ditos "nativos digitais", acostumados com informação instantânea, comunicação global, ambientes customizados, tarefas múltiplas e colaboração. Desde pequenos, estão envolvidos pelas TIC's, feitas para interagirem com todos os setores da sociedade. Desse modo, segundo [4], observações gerais sobre a geração Net podem levar ao argumento de que eles pensam e aprendem de forma diferente das gerações mais antigas.

De acordo com [5], há relatos na esfera popular, e também no meio acadêmico, que sugerem uma ruptura radical entre a geração atual e as anteriores. Tais suposições são feitas baseadas na desenvoltura com que as gerações dominam as mídias, mas os pesquisadores sugerem que essa perspectiva geracional é falha e que não há uma classe resistente à informática. Além disso, de acordo com [3], as pessoas mais velhas, se às vezes recusam as novas tecnologias, é porque têm bons motivos, mas não necessariamente são avessas a elas. Por exemplo, em gerações mais antigas, anteriores aos Baby Boomers, pode-se observar o trato dos idosos com a tecnologia.

De acordo com [6], a relação entre as pessoas idosas e as TIC's tem sido discutida em termos de como a tecnologia pode ser usada por profissionais no auxílio ao idoso para compensar deficiências. Todavia, é importante discutir como os idosos podem eles mesmos usarem as TIC's. Neste âmbito, os idosos podem ter boas experiências com a informática, como relata Rubem Alves [8]:

"[...] a 400 quilometros da cidade de Palmas, as crianças e os professores começaram a ficar preocupa- dos com a situação dos velhinhos agricultores. Fizeram, então, um programa de interação entre crianças e velhos. A idéia era que os velhos contassem histórias para as crianças, que ensinassem as crianças a fazer brinquedos, que ensinassem brincadeiras de antigamente. As crianças, por sua vez, ensinariam coisas de computador para os velhos. Ai algo interessante aconteceu. Os velhos, com suas mãos duras da lavoura, que seriam incapazes de aprender a escrever, descobriram que no computador é muito simples: basta apertar uma tecla para que a letra $m$ apareça. Ao apertar outra, a letra $m$ fica grande. Ao apertar outra tecla, a letra fica colorida... Através do computador, eles começaram a ser alfabetizados pelas crianças"

Desse modo, nota-se que não necessariamente os mais velhos são desinteressados pelo uso da informática na educação. Além disso, percebe-se que a tecnologia pode constituir um meio de integração entre as gerações mais antigas e as mais novas. Isto vale para o contexto educacional, que conta com professores de gerações diferentes.

De acordo com [5], quando é concebida uma dicotomia entre as gerações, distinguindo os mais novos "nativos digitais" dos mais velhos "imigrantes", surge a noção de que o docente de mais idade precisa de treinamento constante para dominar as novas tecnologias, desenvolvidas a cada ano que passa. Mas isso pode ser um equívoco. Ora, ser professor é seguir uma carreira profissional virtuosa que exige constante atualização, porém, como mostram [5], os docentes (em seu estudo) não se veem como vítimas da inclusão de novas tecnologias na escola.

A questão, portanto, não é se os professores de diferentes gerações possuem ou não interesse pelo uso da informática na educação. Interesse há. A questão é se o nível de tal interesse está correlacionado à idade do professor. Por exemplo, de acordo com [7], mais de $96 \%$ dos professores de todas as faixas etárias possuem computador em casa, mas esse número é maior na classe dos mais jovens, com menos de 30 anos de idade. Contudo, pode não ser a idade, mas outros fatores como os conceitos pedagógicos que influenciem a relação de interesse com a informática. Um exemplo disso: docentes com crenças construtivistas são mais interessados em usar computadores em futuras práticas de ensino [4].

Diante desse cenário, seria correto dizer que as gerações mais antigas de professores têm menos interesse em se atualizarem no uso da informática? Ou seriam tais gerações mais interessadas que as mais novas? Este é um aspecto importante a ser considerado, por exemplo, na caracterização do perfil do usuário quando se desenvolve software educacional, ou até mesmo na identificação do público-alvo de um curso de formação docente que aborda assuntos relacionados à tecnologia. Assim, a busca pelo esclarecimento desta dúvida motivou o presente 
trabalho, que tem como objetivo estudar a correlação entre a idade de uma geração de professores e o seu nível de interesse pelo uso da informática na educação.

\section{$2 O$ contexto de estudo}

Este trabalho foi desenvolvido com dados colhidos de um curso de extensão a distância sobre a Produção de Objetos de Aprendizagem [9], realizado no segundo semestre de 2012. Trata-se de um curso gratuito, totalmente online e assíncrono, do qual participaram cerca de 750 professores, da Rede Pública Estadual de Ensino do Paraná e da Universidade Estadual de Maringá. Esse curso foi divido em uma série de 8 módulos de conteúdo, cujos temas eram os seguintes:

$1^{\circ}$ : Informática Básica - conceitos fundamentais de informática (hardware e software).

$2^{\circ}$ : Multimídia - fundamentos técnicos de recursos audiovisuais que podem ser usados para o ensino (imagem, áudio e vídeo digitais).

$3^{\circ}$ : Fundamentos do Processo de Ensino e Aprendizagem - conceitos pedagógicos, focados na didática do uso da informática na educação.

$4^{\text {o: }}$ Sistemas LMS - conceitos que permeiam os Ambientes Virtuais de Aprendizagem (AVA), com atividades práticas de uso do Moodle pelo professor.

$5^{\circ}$ : Ferramentas de Autoria - conceitos que permeiam os Sistemas de Autoria e a integração desses sistemas com AVA's. Atividades práticas do uso do eXe-Learning pelo professor.

60: Normas para Criação de Objetos de Aprendizagem - padrões de publicação e distribuição (ex.: SCORM).

7: Criação, Publicação e Distribuição de Conteúdos para E-Learning - direitos autorais e licenças que podem tornar os Objetos de Aprendizagem em Recursos Educacionais Abertos.

8: Avaliação do Processo de Ensino e Aprendizagem no E-Learning - métodos de avaliação de desempenho das atividades e-learning sobre a aprendizagem.

Os módulos duravam em média duas semanas cada. Durante o curso, foram abertos fóruns de discussão a respeito de cada material didático disponibilizado. Os materiais eram ricos em conteúdo multimídia como hipertextos, imagens, vídeos, entre outros recursos dinâmicos.
Os participantes do curso estavam separados em grupos de 30 a 35 pessoas e havia um tutor para cada grupo que mediava as discussões no fórum. Todas as atividades eram realizadas por meio do Moodle [10], que registrou praticamente todas as ações de sistema de seus usuários numa tabela de logs do banco de dados. Os dados considerados nesta investigação, foram coletados desse banco e referem-se ao período de realização do $1^{\circ}$ ao $4^{\circ}$ módulo do curso.

\section{Indicadores do nível de interesse}

A participação no curso em que se realizou este trabalho não era obrigatória. Como o conteúdo ministrado está intimamente relacionado ao tema "uso da informática na educação", pode-se dizer que a simples participação de um professor nesse curso já é um indicador de que possui interesse no assunto. Assim, para os fins do presente trabalho, considera-se que todos os professores que participaram desse curso possuem interesse pelo uso da informática na educação. Mas o desafio não é constatar se os professores possuem interesse no conteúdo do curso ou não. O desafio é verificar se o nível deste interesse está correlacionado à idade dos professores.

Contudo, o nível de interesse dos professores não é diretamente mensurável, é traço latente, variável complexa que representa aspecto particular e subjetivo do interior de cada indivíduo. Seu valor não pode ser medido, mas existem indicadores que servem de base para inferir as diferenças dos níveis de interesse entre os professores que participaram do curso. De acordo com [11]:

"O indicador é uma medida, de ordem quantitativa ou qualitativa, dotada de significado particular e utilizada para organizar e captar as informações relevantes dos elementos que compõem o objeto da observação."

Deve-se, no entanto, ter cautela para encontrar indicadores que são representativos, pois alguns podem ser falaciosos. Por exemplo: os valores numéricos que o Moodle registrou sobre o tempo gasto por usuário em cada atividade do curso. De fato, espera-se que uma pessoa com mais interesse no assunto tenha passado mais tempo realizando as atividades do curso do que as pessoas que são menos interessadas. Assim, alguém pode pensar que esse registro de tempo seria um bom indicador do nível de interesse do professor, mas isto seria um equívoco. Ora, o tempo que uma pessoa gastou realizando as atividades do curso é sim um indicador, mas o valor registrado pelo sistema como medida de tempo pode não significar o tempo exato, afinal é possível que um usuário inicie uma atividade no sistema e a abandone a qualquer momento sem que o abandono seja registrado. Para que isso aconteça, basta que o usuário deixe a atividade aberta em segundo plano, enquanto faz outras coisas diante do computador, ou até mesmo distante dele. 
Contudo, existem outros registros feitos pelo Moodle, a respeito das ações de cada usuário, que podem ser considerados nesta investigação. Tais registros, porque são pontuais e instantâneos, podem ser classificados e contabilizados. Assim, as quantidades desses registros para cada participante do curso servem de indicadores do nível de interesse pelo conteúdo lecionado em cada módulo.

\subsection{Registros pré-existentes no sistema}

Nesta pesquisa, foram escolhidos alguns indicadores cujos registros estavam presentes no banco de dados do Moodle. Esses indicadores foram nomeados como variáveis da pesquisa e são apresentados conforme se segue:

a) sco: A quantidade de acessos ao material didático de um módulo de conteúdo. Os materiais eram disponibilizados no padrão SCORM [12];

b) vis: A quantidade de visualizações das discussões nos fóruns do curso;

c) pub: A quantidade de publicações em fóruns;

d) env: A quantidade de mensagens enviadas;

Cada variável acima nomeada pode assumir valores diferentes, dependendo do participante e do módulo.

Para fins desta pesquisa, considera-se que, quão maiores os valores dessas variáveis referentes a um professor que participa do curso, maior o seu interesse em aprender o conteúdo do respectivo módulo.

\subsection{Um instrumento complementar}

Para corroborar os indicadores pré-existentes, optouse pela construção de um instrumento complementar de coleta de dados, que gera novos indicadores do nível de interesse dos professores afim de verificar se são coincidentes. Na presente investigação, uma escala Likert [13] é um instrumento aplicável: trata-se de uma pergunta que é apresentada a uma pessoa juntamente com algumas alternativas de resposta que representam níveis de concordância com o que a própria pergunta pressupõe. O respondente pode escolher apenas uma dentre as alternativas de resposta apresentadas.

Assim, uma escala Likert serve para exprimir em valores ordinais os níveis de um traço latente, que não pode ser diretamente mensurado. Desse modo, cada professor que participou do curso pode indicar o seu próprio nível de interesse pelos conteúdos dos módulos, que estão relacionados com o uso da informática na educação.

No entanto, são precisos alguns cuidados na elaboração dessa escala, para evitar que sua validade seja comprometida. Tais cuidados são sutis e subjetivos, por isso, explica-se a seguir como se deu a elaboração da questão a ser respondida pelos participantes do curso, bem como as suas alternativas de resposta.

\section{Cuidado 1: O sentimento de estar sob avaliação}

Quando uma pessoa é confrontada com uma pergunta a respeito de si mesma, essa pessoa pode se sentir sob avaliação [14]. Um sentimento assim pode desviá-la da sinceridade em sua resposta. Diante dessas situações é provável que as respostas sejam aquelas politicamente corretas ao invés das que trazem a verdade à tona.

Desse modo, na elaboração do instrumento do presente trabalho houve o cuidado de fazer com que o professor não se sentisse sob avaliação. Para tanto, foi apresentado um cabeçalho no questionário, contendo uma saudação e uma contextualização que coloca o respondente na posição de avaliador ao invés de avaliado.

Além disso, em conversa com a coordenação do curso, concordou-se que, de maneira útil não apenas a esta pesquisa, a pergunta a ser elaborada para tal instrumento devia permitir a avaliação do próprio curso para que ele pudesse ser melhorado em novas edições. Assim, o cabeçalho do questionário informa que o próprio curso é que está sob avaliação e não o participante:

\section{"Olá cursista,}

Queremos avaliar o desempenho deste curso, verificando se ele tem atingido os seus devidos objetivos. Por isso, colabore conosco respondendo a pergunta abaixo"

\section{Cuidado 2: Perguntando indiretamente}

Mesmo tomando o cuidado de colocar o respondente na posição de avaliador, se a questão apresentada nesse instrumento for direta, os participantes poderiam se sentir em situação de risco e agir de maneira tendenciosa, respondendo que possuem alto nível de interesse, mesmo se não tiverem interesse algum. Por exemplo: "Qual é o seu nível de interesse pelo uso da informática na educação?". Ora, é improvável que um professor responda "é baixo", afinal, ele pode pensar que de algum modo sua resposta o prejudicará no contexto do curso.

Assim, a pergunta apresentada aos participantes não deve ser direta sobre o seu nível de interesse no conteúdo do curso, mas deve estar indiretamente relacionada a esse nível. A respeito disso, o significado da palavra interesse pode auxiliar na elaboração de uma pergunta indireta que tenha relação com o que de fato se deseja questionar.

De acordo com o dicionário Priberam [15], interesse pode significar proveito, utilidade, conveniência ou vantagem. Espera-se, portanto, que uma pessoa interessada em aprender algum assunto específico acredite que tal assunto lhe seja útil e traga alguma vantagem prática. Assim, pode-se dizer que estão mais interessados pelo uso da informática na educação os participantes do curso que mais acreditam que estudar esse tema será algo proveitoso para si. 
Diante disso, a pergunta do instrumento complementar foi elaborada não se tratando diretamente do interesse do participante sobre o conteúdo curso, mas sim do quanto o participante acredita que tal conteúdo lhe será útil em sua vida profissional, o que está relacionado ao seu nível de interesse em usar a informática na educação.

Assim, o modelo de pergunta elaborado para esse instrumento foi o seguinte:

"Considerando o conteúdo que você estudou, neste curso, sobre <Tema do Módulo>, o quanto você acredita que ele pode ser aplicado na sua vida, em um futuro breve, com a finalidade de melhorar a qualidade da sua atividade de ensino?"

\section{Cuidado 3: Privacidade e sigilo}

Além de evitar o sentimento de estar sob avaliação e realizar perguntas de maneira indireta, esta investigação se preocupou em deixar claro que a privacidade do participante é respeitada, de modo que nenhuma resposta será identificada com seu respondente, tampouco publicada.

Isso serve de alento à pessoa que não deseja se comprometer com a pesquisa. Com esses cuidados, a resposta do participante deve fluir sem preocupações e com sinceridade. Por fim, o instrumento foi encerrado com uma observação:

“OBS.: A sua identificação não será exposta.

\section{Seja realista."}

\section{Cuidado 4: A alternativa de abstenção}

Houve ainda outro importante cuidado, referente às alternativas de resposta: algumas pessoas podem não conseguir identificar o seu próprio nível de interesse e, tampouco, expressá-lo em termos de quanto elas acreditam que o conteúdo do curso lhes será útil. Essas pessoas provavelmente tentarão inibir o efeito da resposta. Se as alternativas não contemplarem uma opção específica para essa situação, os participantes provavelmente assinalarão aquela que lhes parecer de menor efeito, geralmente a alternativa do centro.

Desse modo, uma alternativa específica para essa situação foi apresentada na escala desse instrumento, com o seguinte valor qualitativo: "não sei dizer o quanto". Assim, quando essa alternativa for assinalada, a resposta não deve ser considerada como valor representativo do nível de interesse do respondente pelo uso da informática na educação.

\section{Cuidado 5: Alternativas de resposta}

Após esses cuidados, as demais alternativas de resposta foram numeradas de 1 a 7 , representando níveis de interesse que uma pessoa exprime em termos do quanto ela acredita que o conteúdo de um módulo do curso é aplicável nas suas atividades de ensino, variando de "nada aplicável" a "totalmente aplicável":

"Repostas:

( ) Não sei dizer o quanto

( ) 1 - Não é nada aplicável

( ) 2 - Pouquíssimo aplicável

( ) 3 - Pouco aplicável

( ) 4 - Aplicável de modo razoável

( ) 5 - Muito aplicável

( ) 6 - Muitíssimo Aplicável

( ) 7 - Totalmente aplicável”

\section{Indicadores produzidos pelo instrumento:}

As alternativas de resposta de uma escala Likert estão definidas sob uma ordem pré determinada. Trata-se de uma escala ordinal. É válido, portanto, compará-las duas a duas e dizer qual delas é maior e qual é menor.

Assim, a alternativa escolhida por um professor nesse instrumento pode servir como indicador do seu respectivo nível de interesse pelo uso da informática na educação em relação ao nível de interesse dos demais. Esse indicador foi, portanto, nomeado como variável desta pesquisa, conforme se segue:

e) Aplic: valor de ordem (1 a 7) da alternativa escolhida pelo professor como resposta sobre o quanto ele acredita que o conteúdo de determinado módulo do curso é aplicável em sua atividade de ensino.

Essa variável pode assumir valores diferentes, para cada participante em cada módulo do curso.

Considerando todos esses cuidados, foram elaboradas questões de múltipla escolha, do tipo escala Likert, uma para cada módulo do curso (de 1 a 4). Essas questões compuseram um questionário como instrumento de coleta de dados para esta investigação. Esse questionário foi disponibilizado via Moodle e os participantes foram cordialmente convidados a respondê-lo por meio de uma mensagem postada no fórum de notícias. Essa mensagem deixava claro que a participação no questionário não era obrigatória, mas sim de livre e espontânea vontade.

\section{Coleta de dados}

Todos os dados necessários para esta pesquisa foram coletados diretamente do banco de dados do Moodle. Para tanto, foram elaborados códigos de consulta em SQL capazes de extrair, para cada participante, os respectivos valores das variáveis identificadas nesta investigação, considerando separadamente o período em que fo- 
ram ministrados cada um dos módulos do curso, de 1 a 4.

\subsection{Dos indicadores pré-existentes}

As quantidades de acessos aos materiais didáticos dos módulos (sco), de visualizações das discussões nos fóruns (vis), de publicações (pub) e de mensagens enviadas (env) foram todas contabilizadas a partir da tabela de $\operatorname{logs}$ do banco de dados do sistema por meio de consultas que agruparam os dados por usuário e por período de registro.

\subsection{Do instrumento complementar}

O questionário foi implementado com uma ferramenta disponível no próprio Moodle, chamada de Atividade Escolha (Choice).

Desse modo, as respostas dos participantes do curso ficaram armazenadas no banco de dados e puderam ser coletadas por meio de consultas em SQL tais como os valores dos indicadores pré-existentes no sistema.

\section{3 $O$ ano do nascimento dos participantes}

A geração a qual uma pessoa pertence está relacionada ao ano de seu nascimento. É com esse dado que esta investigação deve verificar se o nível de interesse do professor possui correlação. Portanto, esse dado também deve ser nomeado como variável nesta pesquisa, conforme se segue:

f) nasc: o ano de nascimento do participante.

Todavia, neste ponto o presente trabalho encontrou uma dificuldade: nem todos os participantes informaram a data de nascimento no perfil de usuário no Moodle, porque esse não era um dado obrigatório para participação no curso. Assim, nesta pesquisa, foram considerados os dados apenas dos usuários que informaram na página de perfil o ano em que nasceram.

Uma mensagem foi enviada pela coordenação do curso solicitando aos participantes que preenchessem os dados no perfil. Essa medida possibilitou um conjunto de dados maior para esta investigação.

\section{Agrupamentos por gerações}

Esta pesquisa visa constatar se existe ou não correlação entre a idade do professor e o seu nível de interesse pelo uso da informática na educação. No entanto, o cálculo do coeficiente de correlação deve ser feito com um método estatístico não paramétrico, haja vista que todos os dados são valores de contagem ou então ordinais (escala Likert) e não seguem distribuição normal. Por isso, adotou-se o método de Spearman para que fossem calculados os coeficientes de correlação entre as variáveis.

Porém, antes de verificar a correlação entre as variá- veis desta pesquisa, há um detalhe importante a ser considerado: de acordo com [16], a geração Net não é homogênea (assim como as outras também não devem ser). Existe uma série de minorias dentro da população e há uma grande variação tanto dentro como entre as faixas etárias. Tal diferença de entendimento rompe a oposição binária geracional simples: "os mais novos" e os "mais velhos". Não se trata de um universo binário, dualista ou dicotômico, tampouco os grupos são excludentes. Não se espera, portanto, que haja forte correlação entre as variáveis desta pesquisa quando considerados os valores referentes a cada indivíduo. Pessoas distintas, mesmo tendo nascido em um mesmo ano, possuem gostos e costumes diferentes. Ora, tal como o modo de agir e de pensar varia de uma pessoa para a outra, o nível de interesse pelo uso da informática na educação também deve variar.

De fato, pode-se observar que os coeficientes de correlação entre a variável nasc e as demais variáveis desta pesquisa são todos fracos (próximos de zero), conforme apresentados no quadro 1 considerando separadamente cada um dos módulos do curso:

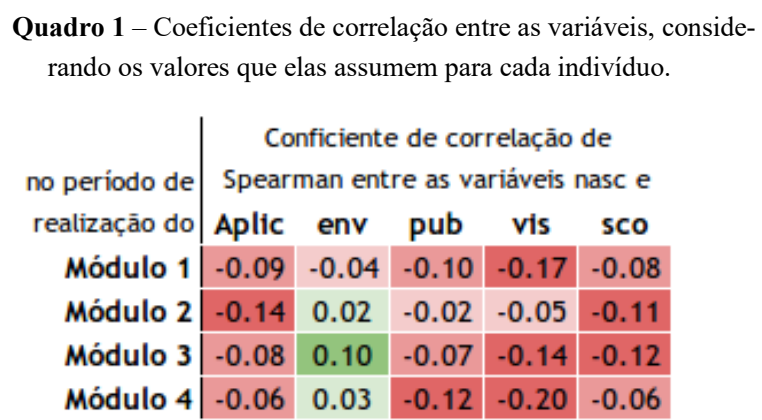

Contudo se, ao invés de indivíduos, forem considerados grupos de participantes, então características sobressalentes de cada grupo devem ser evidenciadas nos dados. Se, em geral, as variáveis de determinado grupo estão correlacionadas, então tal correlação deverá se mostrar forte por meio do cálculo do coeficiente realizado nesta pesquisa. Os dados coletados a respeito dos participantes devem, portanto, ser agrupados de acordo com as gerações às quais pertencem.

Desse modo, consideram-se nesta investigação dados a respeito de grupos de participantes nascidos num mesmo período. Quanto mais longos os períodos, mais perceptíveis devem ser as características dos grupos, consolidando a marca do que se pode chamar de uma geração.

Ora, as pessoas de um século atrás tinham costumes muito diferentes das atuais. O próximo século provavelmente também será muito diferente deste. Mas não é necessário ir tão longe na linha do tempo para que se notem as diferenças entre as gerações. Pessoas podem ser comparadas com base na década de seu nascimento. Falase na música, nos filmes e na tecnologia dos anos 60, 70, 
80,90 e 2000. De década em década o pensamento varia, bem como os costumes e os interesses em geral. Assim, o nível de interesse pelo uso da informática na educação também deve variar de uma geração para outra. Nesse caso, uma geração pode ser representada por pessoas nascidas no mesmo ano, o que é pouco representativo, ou então na mesma década, que é mais representativa.

Assim, para que se verifique se existe correlação entre o nível de interesse pelo uso da informática na educação e a idade de uma geração de professores, faz-se necessária a realização de agrupamentos de dados, de modo a considerar o ano do nascimento e o nível de interesse, não de cada professor separadamente, mas sim de cada grupo de professores que pertencem a uma mesma geração.

\subsection{Como foram feitos os agrupamentos}

Neste trabalho, foram formados agrupamentos de dados com base em " $N$ "-ênios, de acordo com o ano do nascimento dos participantes. Os agrupamentos assim formados representam gerações por:

- $N=1:$ anos

- $N=6$ : sexênios

- $N=2$ : biênios

- $N=7$ : setênios

- $N=3$ : triênios

- $N=8$ : octênios

- $N=4$ : quadriênios

- $N=$ 9: nonênios

- $N=5$ : quinquênios

- $N=10:$ decênios

Considera-se neste trabalho que uma geração é um grupo de pessoas que nasceram no período de, no máximo, $N$ anos após o "nascimento" dessa geração. Definese, portanto, outra variável de pesquisa:

g) Gnasc: o ano de nascimento de uma geração.

Tomando-se o ano de nascimento de um participante (nasc) e os agrupamentos formados por " $N$ "-ênios, é possível identificar à qual geração esse participante pertence. Para $N=1$, o ano do nascimento do próprio participante é o ano de "nascimento" de sua geração $(\boldsymbol{G n a s} \boldsymbol{c}=\boldsymbol{n a s c})$, mas para $N>1$, essa relação deve ser generalizada. Então, para os fins desta pesquisa, define-se que, dado $N$, um participante pertence à geração que "nasceu" em:

\section{- $\operatorname{Gnasc}=\operatorname{nasc}-\bmod (\boldsymbol{n a s c}, N)$}

onde:

mod é a função que retorna o resto da divisão inteira de nasc por $N$.

Por exemplo, para $N=5$, todos os participantes nascidos nos anos 1975, 1976, 1977, 1978 e 1979 pertencem à geração cujo quinquênio se inicia em 1975. Todavia, isso pode variar de acordo com o valor de $N$. Se $N=4$, os participantes que nasceram em 1975 pertencem à gera- ção cujo quadriênio se inicia em 1972, mas os nascidos em 1976, 1977, 1978 e 1979 pertencem à geração cujo quadriênio se inicia em 1976.

Com base nessas definições, os valores extraídos do banco de dados do curso foram agrupados dinamicamente numa planilha eletrônica, considerando o " $N$ "-ênio a que cada indivíduo pertence de acordo com o seu respectivo ano de nascimento e com o valor de $N$.

\subsection{Níveis de interesse das gerações}

Uma vez agrupados em diferentes gerações, deve-se considerar valores representativos dos níveis de interesse pelo uso da informática na educação referentes a cada geração de professores. Os indicadores do nível de interesse de cada participante (sco, vis, pub e env) são dados em escala intervalar. Portanto, é válido calcular a média aritmética simples de cada uma dessas variáveis como forma de encontrar valores representativos para cada agrupamento de participantes formado, que representam diferentes gerações de professores.

Assim, os valores médios dessas variáveis podem servir como indicadores do nível de interesse de uma geração de professores, sendo nomeados como variáveis desta pesquisa conforme se segue:

h) Menv: média aritmética simples de $\boldsymbol{e n v}$;

i) $\boldsymbol{M p \boldsymbol { u } \boldsymbol { b }}$ : média aritmética simples de $\boldsymbol{p u} \boldsymbol{b}$;

j) Mvis: média aritmética simples de vis;

k) Msco: média aritmética simples de $\boldsymbol{s c o}$.

Todavia, não é válido calcular a média da variável Aplic, pois sua escala não é intervalar como as demais, mas ordinal. Deve-se, portanto, efetuar outro tipo de operação sobre essa variável para encontrar um indicador que represente adequadamente um grupo de professores.

Uma possível representação é a frequência relativa, isto é, o percentual de participantes que assinalaram determinadas alternativas. Para os fins do presente trabalho, considera-se que uma geração com maiores percentuais de pessoas que assinalaram alternativas de resposta de valores maiores possui maior nível de interesse pelo uso da informática na educação do que outra geração com menores percentuais de pessoas que assinalaram essas mesmas alternativas de resposta.

Assim, realiza-se uma secção da escala deste instrumento em duas partes: os valores assinalados pelos menos interessados e os valores assinalados pelos mais interessados. Por exemplo, os valores qualitativos de Aplic maiores que "4 - Aplicável de modo razoável" (que é o valor intermediário) são: "5 - Muito aplicável", "6 - Muitíssimo aplicável" e "7 - Totalmente aplicável”. Estes valores $(5,6$ e 7$)$ denotam os maiores níveis de interesse 
dos professores. Então, a soma de suas frequências relativas pode representar o interesse de uma geração.

Aliás, tal secção pode ser mais precisa se considerados apenas os valores mais altos, como 6 e 7, ou apenas o 7. Assim, nesta pesquisa foram nomeadas variáveis que representam as seguintes frequências:

1) pAplic 567: percentual de participantes de uma mesma geração que assinalaram uma alternativa de resposta de valor maior ou igual a 5 .

m) pAplic67: percentual de participantes de uma mesma geração que assinalaram uma alternativa de resposta de valor maior ou igual a 6 .

n) pAplic7: percentual de participantes de uma mesma geração que assinalaram a alternativa de resposta de valor igual a 7 .

\subsection{Agrupamentos fora de análise}

Há ainda que se considerar o fato de que os dados de alguns agrupamentos podem não ser representativos para uma geração. Isso pode ocorrer, por exemplo, quando um grupo é formado por uma minoria. Para minimizar esse efeito, que pode ser um viés, os agrupamentos com menos de 3 pessoas foram considerados como outliers, isto é, seus dados não foram considerados no cálculo dos coeficientes de correlação.

Esse número de três pessoas ainda é baixo e pode não minimizar suficientemente o efeito indesejado de uma geração que é representada por uma minoria, porém, neste ponto o presente trabalho também encontra uma dificuldade: vários dos agrupamentos formados possuem apenas 4 ou 5 indivíduos e, se fossem desconsiderados, toda a análise seria comprometida.

A tabela 1 mostra a quantidade de outliers desta pesquisa, isto é, a quantidade de gerações que não tiveram valores representativos no cálculo dos coeficientes.

Tabela 1: Quantidade de grupos considerados como outliers em cada módulo e em cada tipo de agrupamento por "N"-ênio.

\begin{tabular}{r|cccc}
\hline & Módulo 1 & Módulo 2 & Módulo 3 & Módulo 4 \\
\hline $\mathrm{N}=1$ & 8 & 8 & 8 & 8 \\
$\mathrm{~N}=2$ & 2 & 2 & 3 & 3 \\
$\mathrm{~N}=3$ & 2 & 2 & 2 & 2 \\
$\mathrm{~N}=4$ & 2 & 2 & 3 & 3 \\
$\mathrm{~N}=5$ & 1 & 1 & 1 & 1 \\
$\mathrm{~N}=6$ & 2 & 2 & 2 & 2 \\
$\mathrm{~N}=7$ & 2 & 2 & 2 & 2 \\
$\mathrm{~N}=8$ & 1 & 1 & 2 & 2 \\
$\mathrm{~N}=9$ & 1 & 1 & 1 & 1 \\
$\mathrm{~N}=10$ & 1 & 1 & 1 & 1 \\
\hline
\end{tabular}

O quadro 2 é um exemplo de como foram representados os agrupamentos por sexênio $(N=6)$, considerando os dados relativos ao primeiro módulo do curso. Cada linha da tabela representa uma geração. Notam-se dois grupos, dentre os 8 formados, que possuem menos de 3 participantes e que, por isso, foram considerados outliers.

Quadro 2 - Exemplo de representação por sexênio do interesse das gerações de professores no conteúdo do módulo 1 .

\begin{tabular}{|c|c|c|c|c|c|c|c|c|}
\hline \multicolumn{9}{|l|}{$N=6$} \\
\hline Gnasc & quantidade & pAplic567 & pAplic67 & pAplic7 & Msco & Mvis & Mpub & Menv \\
\hline 1938 & 1 & & & outlier & & & & \\
\hline 1944 & 0 & - & - & - & - & - & - & - \\
\hline 1950 & 10 & $90.00 \%$ & $70.00 \%$ & $50.00 \%$ & 17.60 & 16.60 & 2.20 & 1.20 \\
\hline 1956 & 24 & $95.83 \%$ & $33.33 \%$ & $16.67 \%$ & 11.29 & 10.17 & 1.13 & 1.88 \\
\hline 1962 & 60 & $75.00 \%$ & $38.33 \%$ & $30.00 \%$ & 11.27 & 7.90 & 1.72 & 1.58 \\
\hline 1968 & 53 & $66.04 \%$ & $33.96 \%$ & $16.98 \%$ & 10.81 & 8.55 & 1.25 & 1.57 \\
\hline 1974 & 35 & $71.43 \%$ & $34.29 \%$ & $20.00 \%$ & 12.60 & 11.14 & 1.34 & 0.69 \\
\hline 1980 & 20 & $65.00 \%$ & $30.00 \%$ & $25.00 \%$ & 8.85 & 5.00 & 1.00 & 0.85 \\
\hline 1986 & 1 & & & outlier & & & & \\
\hline 1992 & 0 & - & - & - & - & - & - & - \\
\hline 1998 & 0 & - & - & - & - & - & - & - \\
\hline
\end{tabular}

\section{Hipóteses do estudo}

A questão chave desta pesquisa pode ser enunciada da seguinte maneira: Existe correlação entre a idade de uma geração de professores e o interesse geral dessa geração pelo uso da informática na educação? Se sim, quem tem mais interesse? Seriam as gerações mais jovens ou as gerações mais antigas?

Essa questão está relacionada à verificação do coeficiente de correlação entre as variáveis em estudo e à sua respectiva interpretação, se é positiva ou negativa e se é fraca ou forte. Embora funções matemáticas possam subsidiar a definição das hipóteses desta pesquisa, interpretar a força de um coeficiente de correlação é uma questão de teor qualitativo. Em alguns casos, admitem-se faixas de valores que representem diferentes níveis, por exemplo: de 0 a 0.3 , fraca; de 0.3 a 0.7 , moderada; e de 0.7 a 1 , forte. Porém, para os fins do presente trabalho interessa arbitrar a dualidade fraca/forte, sem valores intermediários. Estipula-se, para tanto, o valor 0.5 como crivo da interpretação do coeficiente de correlação entre a variável Gnasc e as demais variáveis. Assim sendo:

- forte e positiva: coeficiente maior que 0.5 ;

- forte e negativa: coeficiente menor que -0.5 ;

- fraca: coeficiente entre -0.5 e 0.5 .

Diante disso, as seguintes funções são propostas para subsidiar a definição das hipóteses desta pesquisa:

$\operatorname{Spearman}\left(v_{1}, v_{2}, M, N\right)$

o coeficiente de correlação de Spearman entre as variáveis $\boldsymbol{v}_{\mathbf{1}}$ e $\boldsymbol{v}_{\mathbf{2}}$ referentes ao período do módulo $\boldsymbol{M}$ do curso (1 a 4) quando os agrupamentos são formados por “ $N$ "-ênios. 


\section{$\operatorname{Positiva}(v, M, N)$}

$= \begin{cases}1, & \text { Spearman }(\text { Gnasc }, v, M, N)>0.5 \\ 0, & \text { caso contrário. }\end{cases}$

Negativa $(v, M, N)$

$= \begin{cases}1, & \text { Spearman }(\text { Gnasc }, v, M, N)<-0.5 \\ 0, & \text { caso contrário. }\end{cases}$

$\operatorname{Fraca}(\boldsymbol{v}, M, N)$

$= \begin{cases}1, & -0.5 \leq \text { Spearman }(\text { Gnasc }, ~ \\ 0, & \text { caso contrário. }\end{cases}$

Então, as quantidades de correlações constatadas neste trabalho, entre a variável Gnasc e as demais variáveis em todos os casos desse estudo ( $N:[1 . .10]$ e $M:[1 . .4])$, podem ser descritas como se segue:

$$
\begin{aligned}
\text { Positivas } & =\sum_{i=1}^{7} \sum_{m=1}^{4} \sum_{n=1}^{10} \operatorname{Positiva}(V(i), m, n) \\
\text { Negativas } & =\sum_{i=1}^{7} \sum_{m=1}^{4} \sum_{n=1}^{10} \operatorname{Negativa}(V(i), m, n) \\
\text { Fracas } & =\sum_{i=1}^{7} \sum_{m=1}^{4} \sum_{n=1}^{10} \operatorname{Fraca}(V(i), m, n)
\end{aligned}
$$

Onde,

$$
\begin{array}{ll}
V(1)=\text { Msco, } & V(5)=\text { pAplic567, } \\
V(2)=\text { Mvis }, & V(6)=\text { pAplic67, } \\
V(3)=\text { Mpub }, & V(7)=\text { pAplic7. } \\
V(4)=\text { Menv, } &
\end{array}
$$

Com base nisso, propõe-se o seguinte raciocínio:

Se a maioria dos coeficientes calculados indicarem uma correlação forte e positiva, isso evidencia que: no contexto desta investigação, quanto maior é o ano do nascimento, maior é o interesse dos professores em usar a informática na educação. Assim, os professores mais jovens são os que possuem mais interesse. Todavia, se a maioria dos coeficientes calculados indicarem uma correlação forte e negativa, isso evidencia o contrário: os mais velhos são os que têm mais interesse. Em caso diferente desses, em que a maioria dos coeficientes calculados indicam correlação fraca, pode-se dizer que não há evidência de que uma geração de professores seja mais interessada que a outra em usar a informática na educação.

Com intuito de responder a questão chave desta pesquisa, formulam-se as seguintes hipóteses de estudo:

- $H_{0}$ : Não existe forte correlação entre a idade das gerações de professores e o interesse pelo uso da informática na educação.

$$
\text { Fracas } \geq \mid \text { Positivas }- \text { Negativas } \mid
$$

- $H_{1}$ : Existe forte correlação entre a idade das gerações de professores e o interesse pelo uso da informática na educação. Os professores mais jovens têm mais interesse do que os professores mais velhos.

\section{Positivas $>$ Fracas + Negativas}

- $H_{2}$ : Existe forte correlação entre a idade das gerações de professores e o interesse pelo uso da informática na educação. Os professores mais velhos têm mais interesse do que os professores mais jovens.

\section{Negativas $>$ Fracas + Positivas}

\section{Resultados}

Dentre os professores inscritos no curso, foram 207 os que participaram desta pesquisa. A figura 1 mostra a distribuição desses participantes de acordo com as décadas de nascimento. A figura 2 mostra a frequência absoluta para cada alternativa de resposta do questionário.

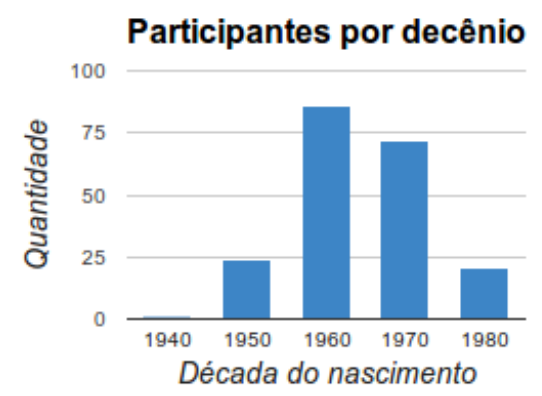

Figura 1 - Quantidade de participantes por década de nascimento

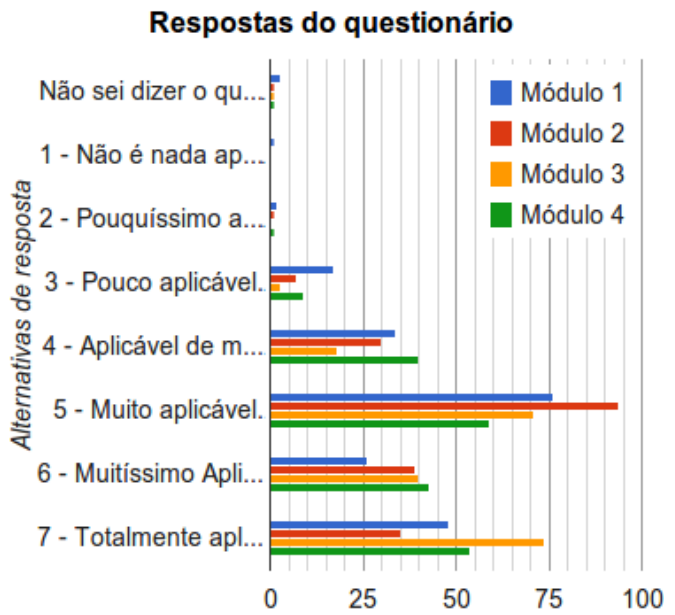

Figura 2 - Respondentes de cada alternativa do questionário

A seguir, as figuras de 3 a 10 mostram os coeficientes de correlação entre a variável Gnasc e os indicadores que representam o nível de interesse das gerações de professores pelo uso da informática na educação. 


\section{Correlação no Módulo 01}

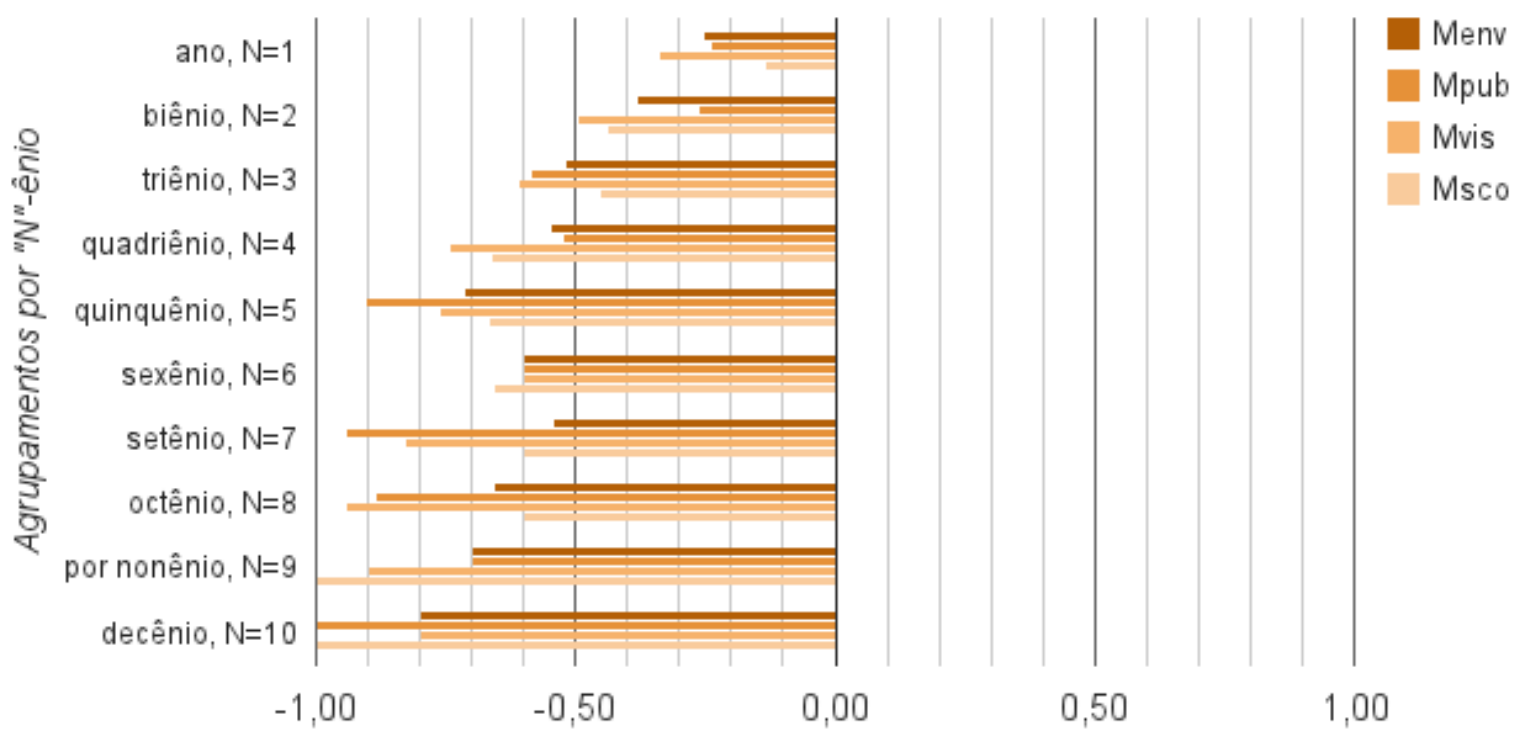

Coeficientes de correlação

Figura 3 - Coeficientes de correlação entre a variável Gnasc e as variáveis Menv, Mpub, Mvis e Msco referentes ao Módulo 1

\section{Correlação no Módulo 02}

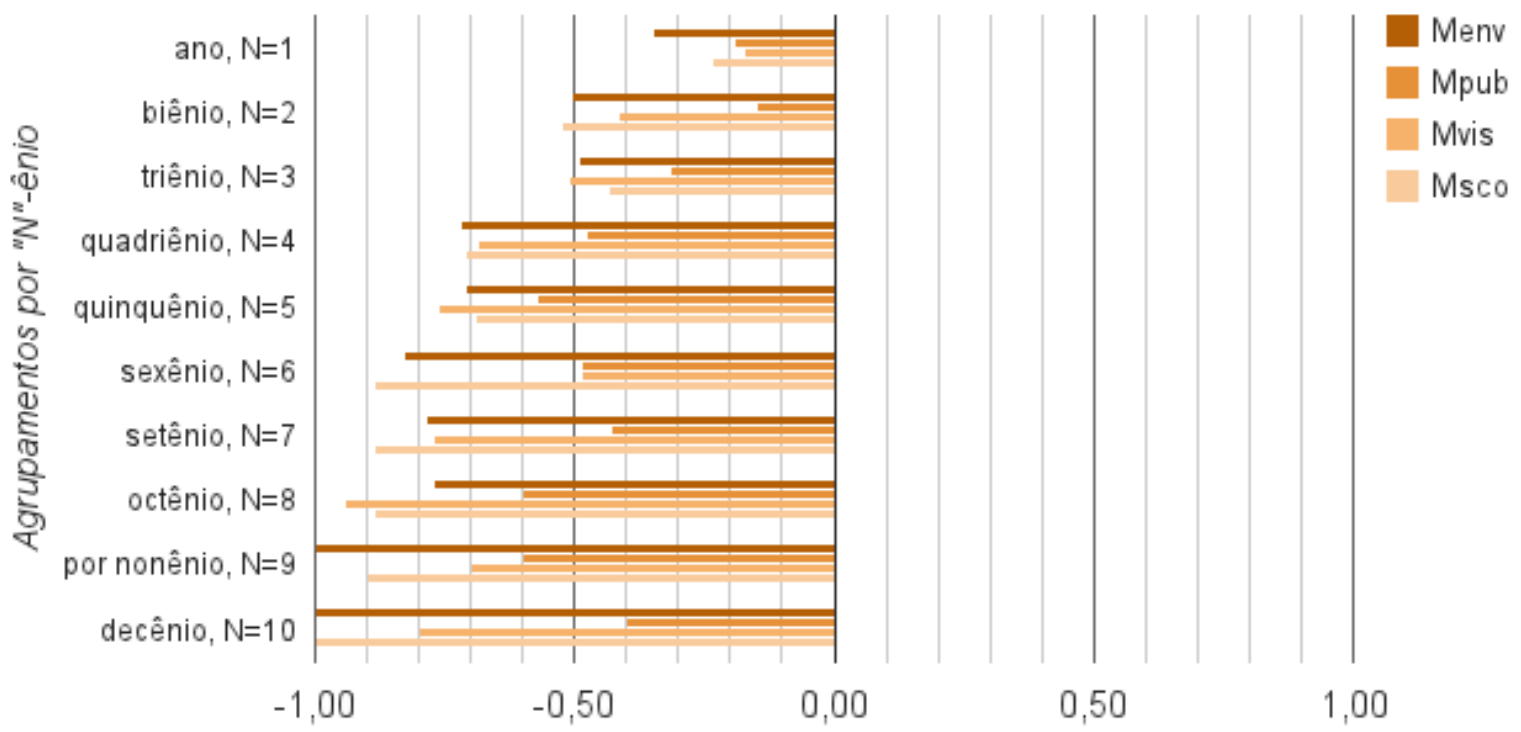

Coeficientes de correlação

Figura 4 - Coeficientes de correlação entre a variável Gnasc e as variáveis Menv, Mpub, Mvis e Msco referentes ao Módulo 2 


\section{Correlação no Módulo 03}

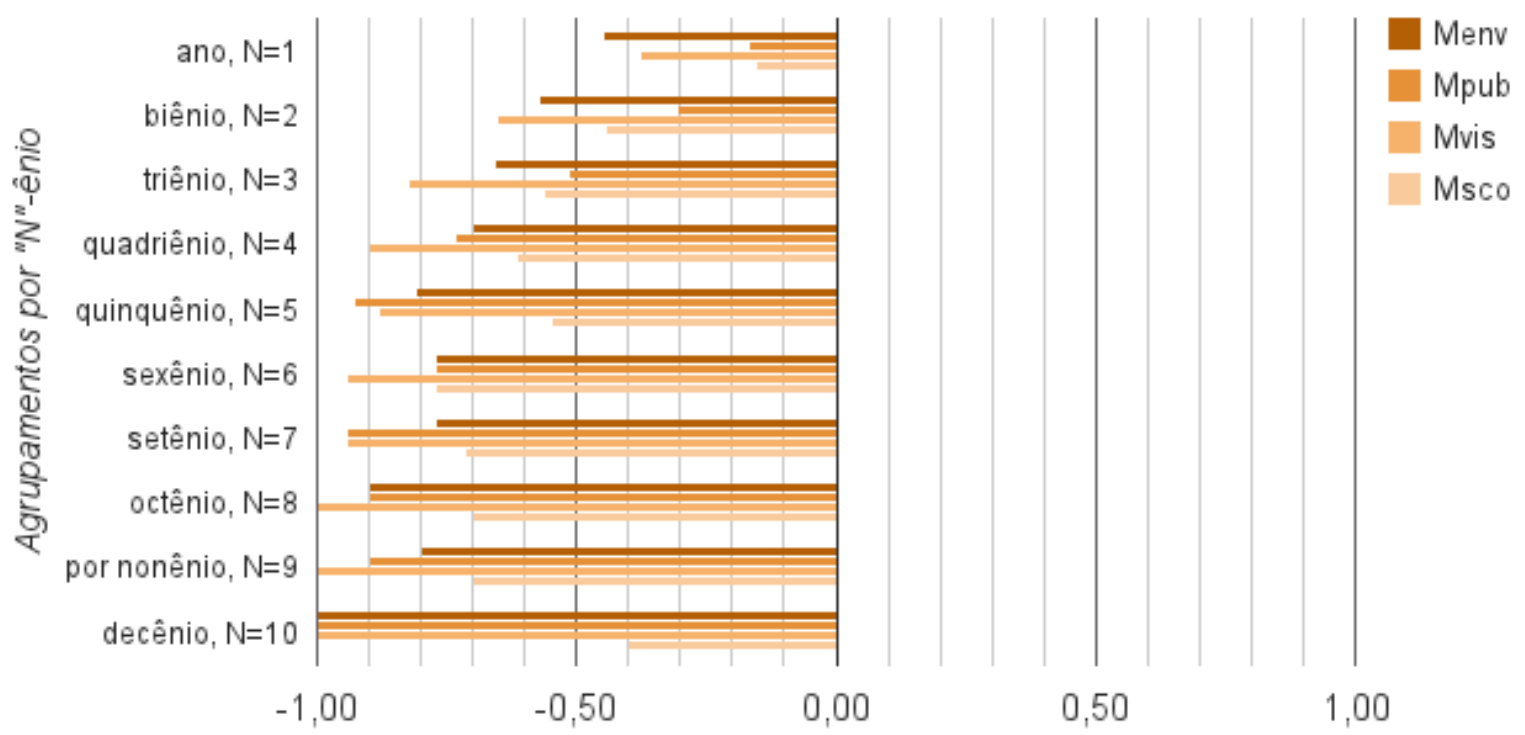

Coeficientes de correlação

Figura 5 - Coeficientes de correlação entre a variável Gnasc e as variáveis Menv, Mpub, Mvis e Msco referentes ao Módulo 3

\section{Correlação no Módulo 04}

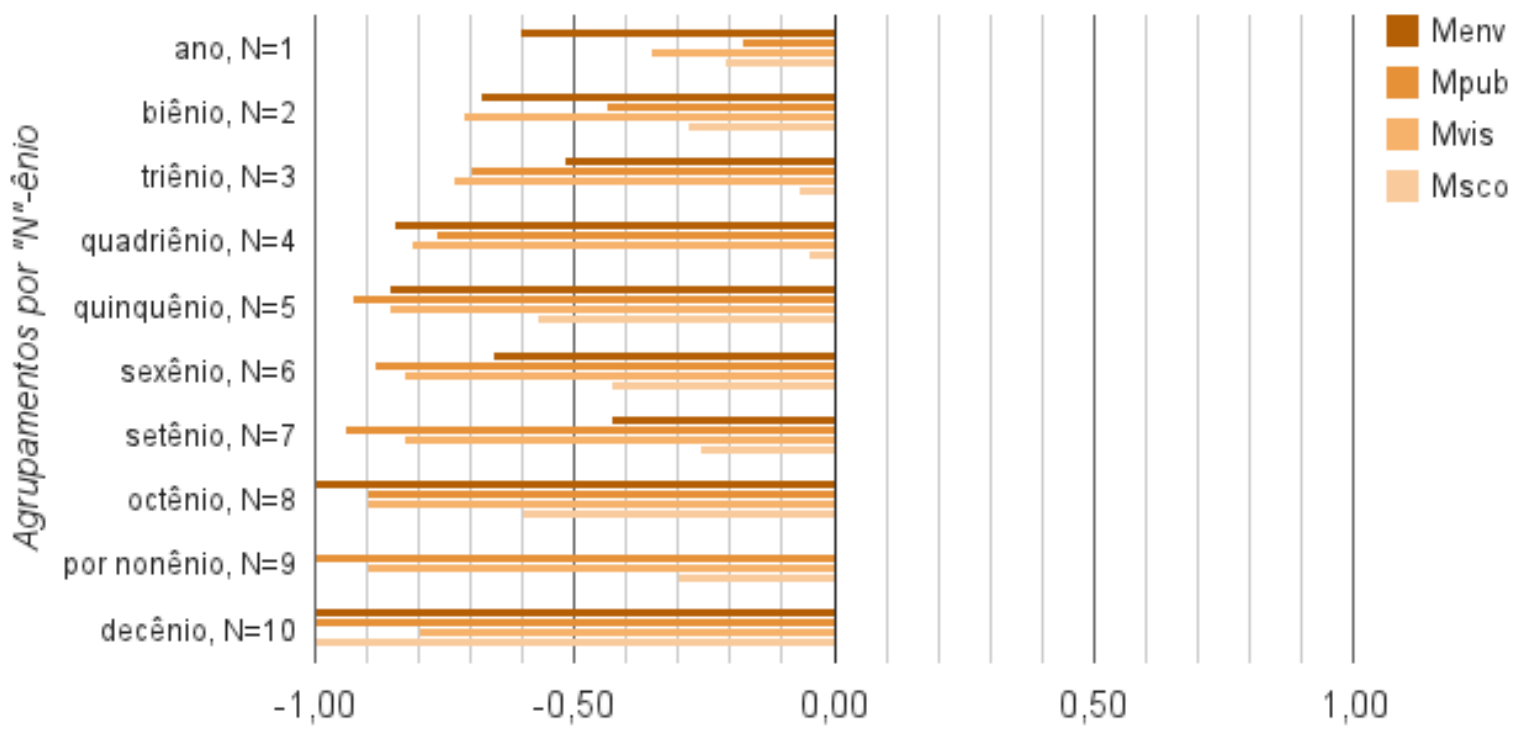

Coeficientes de correlação

Figura 6 - Coeficientes de correlação entre a variável Gnasc e as variáveis Menv, Mpub, Mvis e Msco referentes ao Módulo 4 


\section{Correlação no Módulo 01}

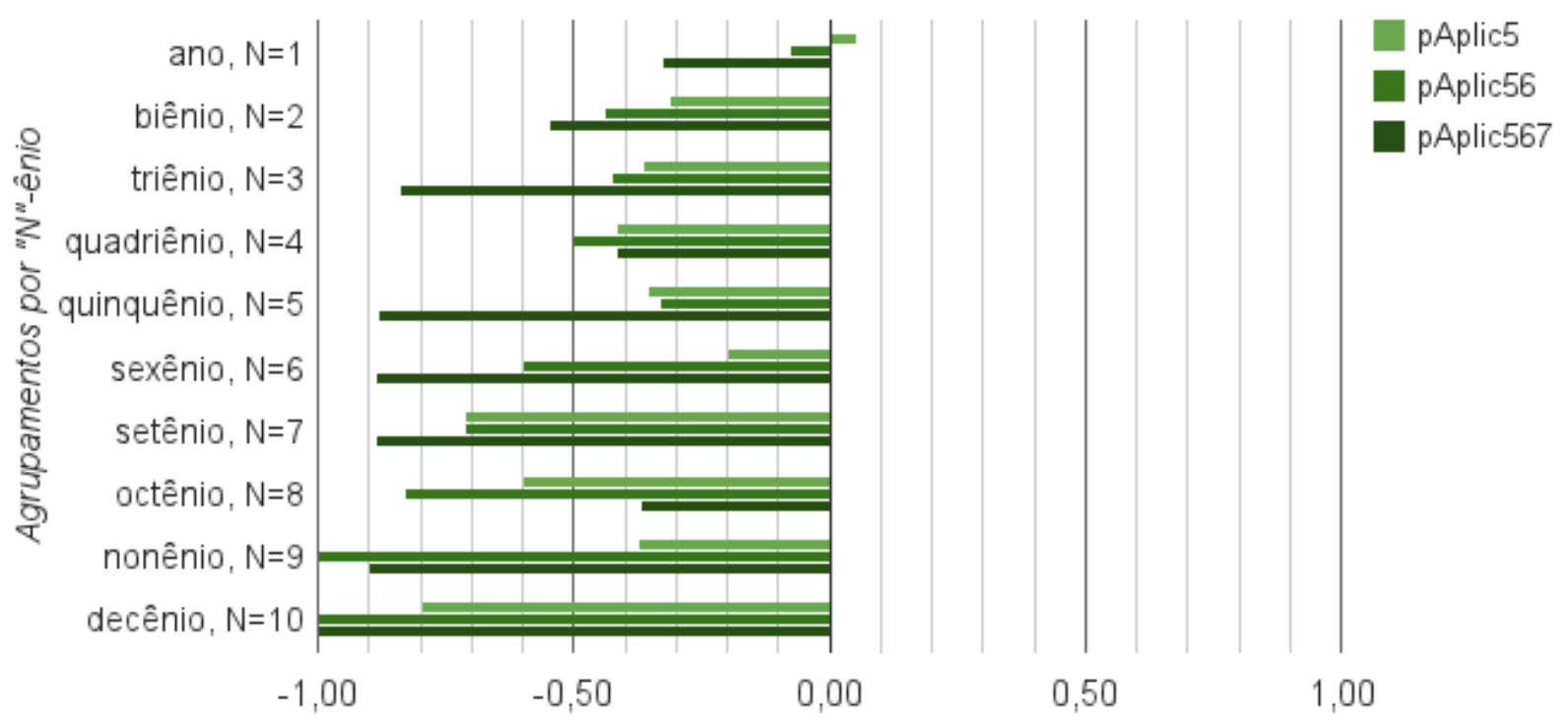

Coeficientes de correlação

Figura 7 - Coeficientes de correlação entre a variável Gnasc e as variáveis pAplic567,pAplic67 e pAplic7 referentes ao Módulo 1

\section{Correlação no Módulo 02}

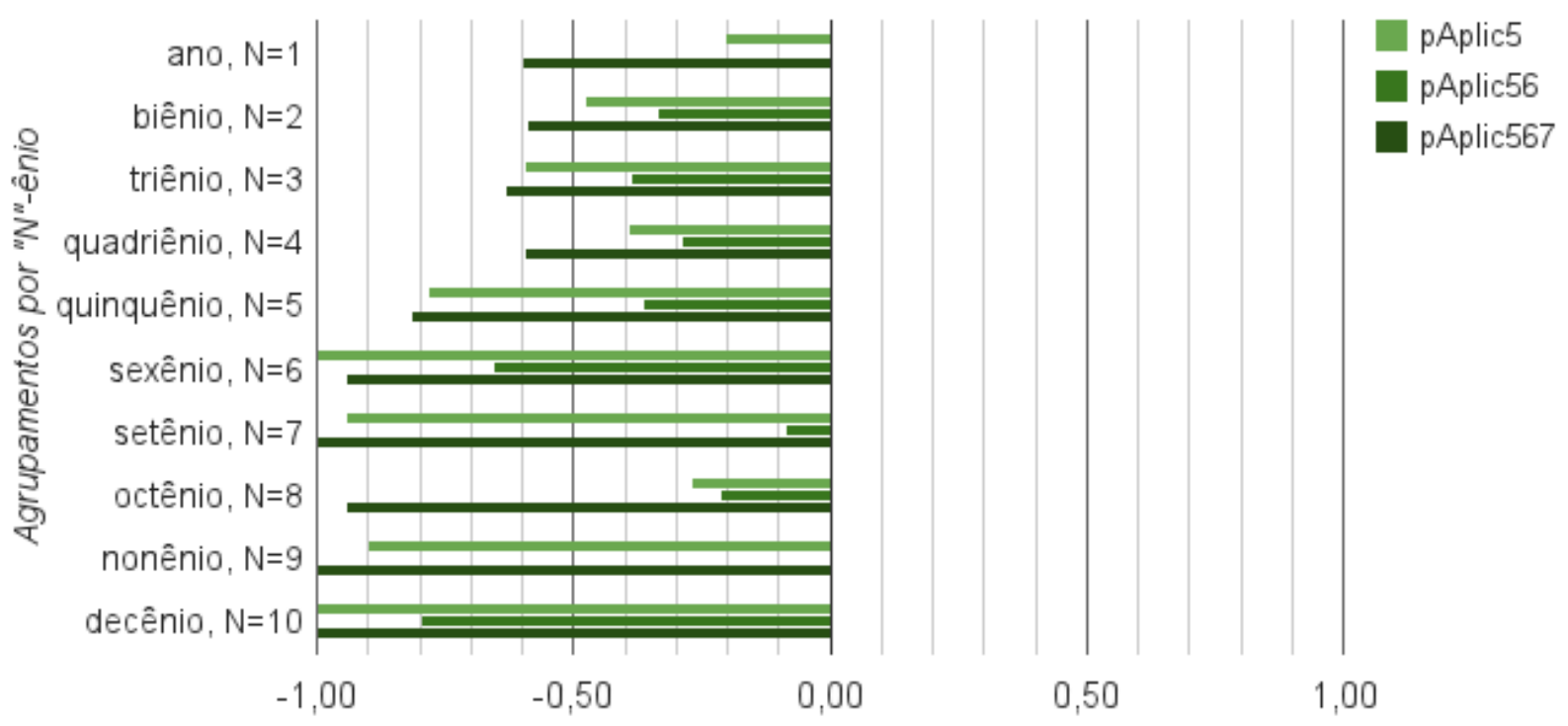

Coeficientes de correlação

Figura 8 - Coeficientes de correlação entre a variável Gnasc e as variáveis pAplic567,pAplic67 e pAplic7 referentes ao Módulo 2 


\section{Correlação no Módulo 03}

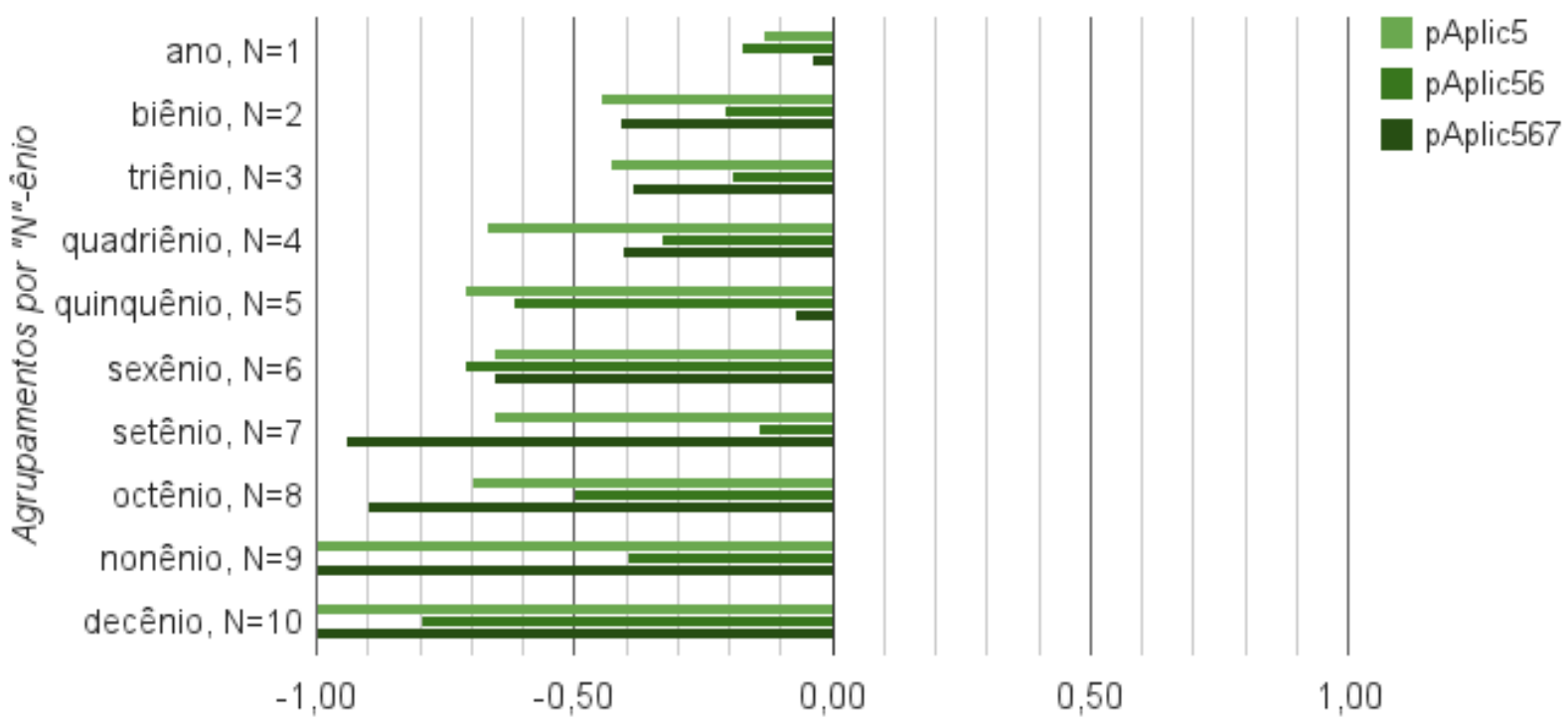

Coeficientes de correlação

Figura 9 - Coeficientes de correlação entre a variável Gnasc e as variáveis pAplic567,pAplic67 e pAplic7 referentes ao Módulo 3

\section{Correlação no Módulo 04}

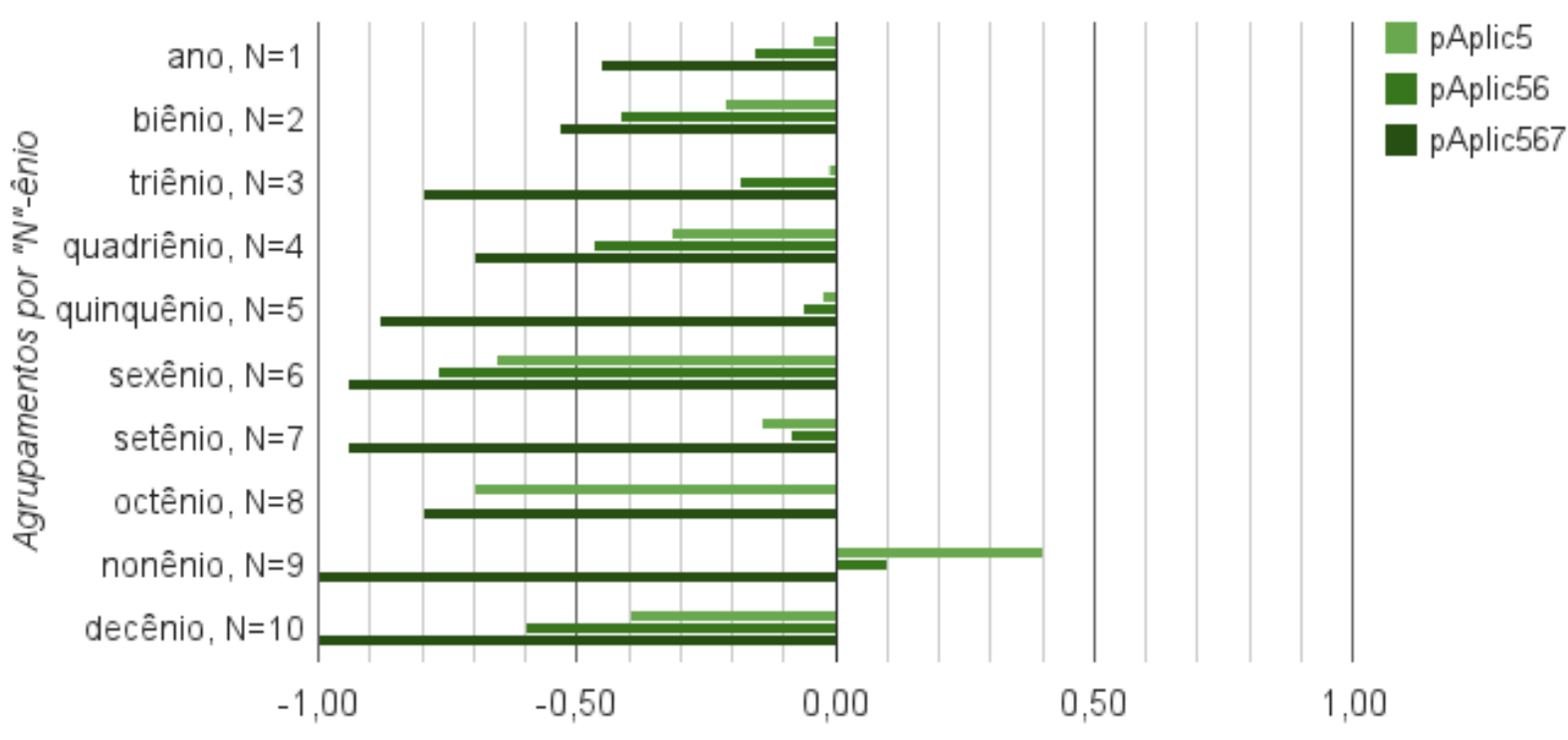

Coeficientes de correlação

Figura 10 - Coeficientes de correlação entre a variável Gnasc e as variáveis pAplic567,pAplic67 e pAplic7 referentes ao Módulo 4 


\section{Conclusão}

Os gráficos dos coeficientes de correlação gerados neste trabalho são importantes para observar como a correlação entre Gnasc e as demais variáveis se torna mais forte à medida em que são ampliados os períodos " $N$ " das gerações. Isto ocorreu de modo geral em todos os módulos com todas as variáveis. Tal observação evidencia que os indicadores escolhidos coincidem, o que é um sinal de fidedignidade, e também corrobora a ideia de que, quanto mais longos são esses períodos " $N$ ", mais perceptíveis são as características de uma geração.

Ao todo, foram calculados 280 coeficientes de correlação por meio de um método não paramétrico (Spearman). Pelos valores encontrados, constatam-se as seguintes quantidades de correlações fortes:

\section{- Positivas $=0$}

$$
\text { - Negativas }=180
$$

e a seguinte quantidade correlações fracas:

\section{- Fracas $=100$}

Nota-se que a maioria dos coeficientes calculados indicam correlação forte e negativa. Além disso, apenas 3 dentre os coeficientes que indicaram correlação fraca são positivos. Todos os demais também são negativos.

Se, em geral, a correlação entre o ano de nascimento de uma geração de professores e os indicadores do nível de interesse pelo uso da informática na educação é forte e negativa, isso significa que tal interesse cresce com o retrocesso da linha do tempo, isto é, quanto mais antiga é uma geração de professores, maior é o seu interesse pelo uso da informática na educação.

Assim, esta investigação rejeita a hipótese nula $\left(H_{0}\right)$ e aceita a hipótese alternativa $H_{2}$, pois:

\section{Negativas $>$ Fracas + Positivas}

Enfim, no contexto deste estudo, de professores interessados pelo uso da informática na educação, a conclusão é que os mais velhos têm mais interesse no assunto do que os mais jovens.

\section{Discussão e trabalhos futuros}

É de suma importância para a área da informática na educação que os trabalhos destinados a investigar a utilização de novas tecnologias no processo educacional realizem pesquisas com base empírica. Contudo, não é sempre que pesquisas assim são realizadas. Talvez pela dificuldade de sua condução ou por se considerar que o teor do planejamento e do controle em detalhes na busca de precisão proporcione grande validade interna em detrimento da validade externa. De fato, quanto mais preci- sa e controlada a pesquisa, maior a sua validade interna e menor a possibilidade de generalização de seus resultados. Assim, o presente trabalho, em vários momentos, reduziu a capacidade de generalização de seus resultados, entre os quais podem ser citados:

- a população em estudo;

- os temas dos módulos do curso;

- a escolha dos indicadores no Moodle;

- os cuidados do instrumento complementar.

Geralmente, pesquisas deste tipo acabam por representar situações bastante particulares, que até podem trazer resultados passíveis de generalização, embora isto deva ser feito com muita cautela. Para tanto, este trabalho especifica, em seu contexto de estudo, questões de tempo, espaço, pessoas, bem como o cenário de sua realização. A saber: sua população, composta por professores da rede pública de ensino do Estado do Paraná e professores da Universidade Estadual de Maringá; o ano de sua realização, 2012; o conteúdo do curso, que se trata da produção de objetos de aprendizagem, por cujos temas dos módulos os professores se interessaram no ato da inscrição; e sua forma de realização, via Moodle, totalmente a distância. Essas informações podem subsidiar uma futura identificação de modelo de similaridade proximal, que por ventura pode ampliar a validade externa desta pesquisa.

Também é possível realizar uma pesquisa de levantamento com dados de uma amostra representativa dos professores no contexto nacional ou global, considerando-se na investigação os níveis de interesse dos professores representados até mesmo por outros indicadores. Isto pode ser feito, por exemplo, por meio de amostragem probabilística. Além disso, estudos de correlação não respondem questões de causa e efeito. Esta pesquisa, portanto, não diz se os professores mais velhos são mais interessados pelo uso da informática na educação por causa das atuais condições do mercado de trabalho ou se por causa de determinada visão pedagógica. Sabe-se apenas que, no contexto deste estudo, os professores mais velhos têm mais interesse que os mais jovens. Para responder qual seria a causa disso, recomenda-se que sejam realizados experimentos.

É importante salientar que os resultados encontrados no presente trabalho, frente às características das variáveis envolvidas, representam uma determinada situação que possui condições que lhe conferem certa identidade, tornando a pesquisa um estudo de caso, o que, apesar de reduzir sua capacidade de generalização, contribui com informações preciosas para o desenvolvimento de software educacional e para a oferta de cursos de formação docente cujos contextos devem considerar o interesse dos professores de determinadas gerações. 


\section{Agradecimentos}

Este trabalho foi realizado com apoio da CAPES - Coordenação de Aperfeiçoamento de Pessoal de Nível Superior, por meio de bolsa concedida a André Cruz Mendes.

\section{Referências}

[1] Comitê Gestor da Internet no Brasil. Parte 2: TIC Domicílios: Análise dos Resultados TIC Domicílios 2012. In: . TIC Domicílios e Empresas 2012: pesquisa sobre o uso das tecnologias de informação e comunicação no Brasil [livro eletrônico]. São Paulo: CGI.br, 2013. p. 153-182.

[2] B. Pletka, Educating the Net Generation: How to Engage Students in the 21 st Century. $2^{\mathrm{a}}$ ed. Santa Monica Press LLC, Santa Monica, CA, 2007.

[3] C. E. Peixoto, "Envelhecimento, políticas sociais e novas tecnologias". Editora FGV, Rio de Janeiro, 2005.

[4] H. J. So et al. Little experience with ICT: are they really the Net Generation student-teachers? Computers \& Education, v. 59, n. 4, p. 1234$1245,2012$.

[5] T. A. Amiel, S. Ferreira, Nativos e imigrantes: questionando a fluência tecnológica docente. Revista Brasileira de Informática na Educação, v. 21, n. 03, p. 1, 2014.

[6] B. Jaeger, Young Technologies in Old Hands: An International View on Senior Citizen's Utilization of ICT. DJØF publ., Universidade de Indiana, 2005.

[7] CETIC.br. "TIC Educação 2012 - Professores". http://www.cetic.br/tics/educacao/2012/professor es/B2/, Ago. 2014.

[8] G. Dimenstein, R. Alves, Fomos maus alunos. Papirus Editora, Campinas, SP, 2003.

[9] R. McGreal, Learning objects: A practical definition. International Journal of Instructional Technology and Distance Learning (IJITDL), v. 9, n. 1, 2004.

[10] Moodle.org. "About Moodle". https://docs.moodle.org/27/en/About_Moodle, Ago. 2014.

[11] H. Ferreira, M. Cassiolato, R. Gonzalez. Uma experiência de desenvolvimento metodológico para avaliação de programas: o modelo lógico do programa segundo tempo. Texto para Discussão, Instituto de Pesquisa Econômica Aplicada
(IPEA), 2009.

[12] W. Bailey. What is ADL SCORM? CETIS Standards Briefings Series, 2005:B04. Bolton, 2005.

[13] L. Pasquali, Instrumentação Psicológica: Fundamentos e práticas. Artmed, Porto Alegre, 2010.

[14] S. Vieira, Como Elaborar Questionários. Editora Atlas, São Paulo, 2009.

[15] Priberam. "Significado / definição de interesse no Dicionário Priberam da Língua Portuguesa." http://www.priberam.pt/dlpo/interesse. Ago. 2014. Priberam Informática, S.A.

[16] C. Jones et al., Net generation or digital natives: is there a distinct new generation entering university?. Computers \& Education, v. 54, n. 3, p. 722-732, 2010. 